\title{
Liability for Unauthorized Agency: In the View of China-Germany Comparative Law
}

\author{
Xiangzhen Yue ${ }^{1, a}$ \\ ${ }^{1}$ No.9 Zhengtong Road, Erqi District, Zhengzhou City, Henan Province, China \\ ay745380972@126.com
}

Keywords: unauthorized agency, German Civil Law, liability for statutory guarantee, subjective fault

\begin{abstract}
The establishment of the liability for unauthorized agency is essential to the protection of transaction security. It arises from the breach of declaration made by agent about his authorization, which leads to the existence of the guarantee based on law. This point has been reflected in the German Civil Law, and Section 179 has classified the liability according to the subjective fault of the agent. However, the Chinese legislation is still immature. It actually combines the contents of the first and second paragraphs of Section 179 of the German Civil Law. Whether the unauthorized agent realizes the lack of agency or not, they all bear the same legal responsibility, and the unified regulation creates controversy in legal practice. Through the study on the nature and the comparative research of law between Germany and China, this kind of liability can be understood clearly.
\end{abstract}

\section{Introduction}

In the case of unauthorized agency, the principal shall not be legally bound when he declines to ratify, and the unauthorized agent does not bear the liability either because of the relativity principle of contract. In order to make the agent take the responsibility for his unauthorized behavior, a new liability is being offered. However, it still remains an ongoing challenge due to the immature legislation in China, though the General Rules of the Civil Law of the PRC, enacted recently, does have improvement. Reference to German Civil law, article 171 of this Chinese civil code details the liability for the unauthorized agent. For the first time, it stipulates the method of the liability and the extent of the compensation, increasing the practical value of the norms. But it still leaves much to be desired. Based on the comparison between Germany and China, this article will discuss the nature of the legal responsibility and analyze the different pieces of legislation. And it is worthwhile devoting much effort to it.

\section{Nature of Liability for Unauthorized Agency}

To begin with, we need to clarify whether the liability is a kind of fault liability or not. Some scholars suggest that the answer is yes. However, most scholars agree that the liability is a kind of no-fault liability. The following reasons may account for it. First, the third party in good faith has difficulty in bearing the burden of proof. Second, the actor usually owns a closer relationship with principal, and the information of agency is more likely to be accessed. Third, the reasonable reliance emerges due to the declaration made by the agent about the power of agency, and it prompts the third party to engage in the legal activity. In this situation, subjective fault isn't necessary while the broken reliance is a central element for the establishment of liability. Fourth, the system of liability without fault encourages agent to perform juristic acts cautiously and reduces the occurrence of the unauthorized agency.

Specifically, these theories held by scholars are various: The contractual liability, which regards the agent as the party of bilateral legal relationship. Tort liability, which attributes the activities of 
unauthorized agency to the general torts. The liability of Culpa in Contrahendo, suggesting that man is supposed to pay constant attention to his authorization and if he fails to fulfill the duty, he should be liable for his negligence. Liability for implied warranty, saying that there is an implied declaration of intention which indicates the guarantee for the effectiveness of the legal act when someone performs juristic act in the principal's name. But they are more or less defective.

After referring to the accepted theory in Germany, some scholars bring up the doctrine called "the liability for statutory guarantee”. During the process of interaction with others, agent claims that he has the authorization and his act would be responsible by the principal, on which others choose to bring themselves into the special legal relationship based. Agent is supposed to liable for his claim. [1] There are three reasons for that. First, the subjective fault should not be taken into account as discussed above. Second, the agent is in possession of an independent status that distinguishes himself from the principal in agency activity. The person chosen by the third party is the principal rather than the agent. Third, the liability for unauthorized agency is derived from the law instead of the implied declaration. And this point of the liability for statutory guarantee is reflected in Section 179 of German Civil Law.

\section{The Liability under the Section 179 of German Civil Law}

If the actor is not aware of the lack of the authorization, he only need to compensate for the damage which the other party suffers on account of relying on his power, and it is limited by the amount of the interest that the other party can obtain in the effectiveness of the juristic act, according to the paragraph 2, Section 179. While the other party is entitled to claim that the actor bears the responsibility by specific performance or compensation for the loss of performing interest when the actor is clearly know or supposed to know the lack of authorization in the view of systematic interpretation, based on the paragraph 1 . Moreover, the paragraph 3 provides the situations where the actor is free from the liability.

\subsection{The Extent of Responsibility Classified by the Subjective Fault}

When the actor is fully aware of the fact that he is unauthorized or he is supposed to know it, he owns a negative subjective state, that is, intentional misconduct or gross negligence, condemned by law. Therefore, he should bear the responsibility to satisfy the other party's need. From the perspective of liability for statutory guarantee, the claim made by the agent that the power of agency does exist leads to the emergence of a valid guarantee based on the law, and agent is supposed to be liable for it. And by giving the other party the choice, the German Civil Law strengthens the protection of legitimate interests of the majority in the open market to the maximum extent.

If the unauthorized agent does not realize the fact, he only needs to compensate for the loss of reliance interest, and the amount is limited to the benefit of performance. Contrary to the situation above, the reason why the actor erroneously thinks that he has the power of agency can often be attributed to the principal. For example, the principal cancels the authorization but fails to notify the agent in time, or the principal is limited in capacity for civil conduct when he makes the authorization and does not have the consent of his statutory agent, the actor cannot recognize it even though he fulfills the duty of care excellently. In order to reach a certain equilibrium, we are supposed to take the interest of agent into account while talking about the protection of reliance interest of the other party.

The system established by the German Civil Law should be acknowledged. While balancing the interest of each party, it has maintained the credibility of agency system.

\subsection{Exemption from Liability}

The liability is certainly a kind of no-fault liability, but situations do exist where the actor is free from the liability. Provided by the third paragraph of Section 179, the subjective fault of the other party or the limitation of civil capacity of actor is one of them. 
The other party is supposed to consider the risk of invalidation of the legal act when he knows the lack of authorization. According to the rule of assumption of risk, when the aggrieved one knows the act possibly causes damage but still performs it, he should bear the adverse consequence himself. It is also applied to the circumstance that one is ought to know the deficiency.

When the actor is the person limited in disposing capacity and performs juristic act without ratification by his statutory agent, he is also exempt from liability. The reason is that the protection of the person with limited civil capacity is given priority, compared with the protection of transaction security.

Moreover, others cannot suffer from the situation of unauthorized agency if they have withdrawn their acts. But there is an exception that the juristic act performed by the actor constitutes a tort.

\section{Liability in Article 171 of General Rules of the Civil Law of the PRC}

The article 171 further stipulates that the other party in good faith has the right to claim for damages or specific performance, and the amount of compensation shall not exceed the benefit resulting from the effectiveness of the juristic act when the agent is recognized. And the fourth paragraph points out that if the other party has subjective fault, he shall bear the civil liability with the unauthorized agent. It is a pity that neither the classification nor the exemptions are pointed out. While recognizing its constructive progress, we should not ignore the flaw which may be existed.

\subsection{The Legal Premise of Liability for Unauthorized Agency}

First, the unauthorized agent must be the person with full capacity for civil conduct, whose declaration of will is true and without defect. The juristic act can be performed by agent, which means it does not have strong personal characteristics. And the content of it shall not violate the law. Basically, the act performed by agent cannot be invalid or canceled for other reasons, except the refusal of ratification.

Second, because of this refusal, the act cannot bind upon the principal. Compared with the third draft of the General principles of civil law of the PRC, which provides that it is invalid directly, the law enacted officially still follows the article 48 of the Contract Law, saying that the act performed by agent without ratification cannot work for the principal. According to this provision, when the principal decline to ratify, the other party is still entitled to claim that the act causes corresponding legal consequence to the agent. [2] This point indicates the principle of the contractual liability by treating the actor as the party of the contract. But the liability does not arise from the breach of contract, according to the theory of the liability for statutory guarantee, its establishment does not need the prerequisite that the contract has a legal binding on the agent, the act is supposed to be invalid. [3]

Third, the other party in good faith has not canceled the juristic act. After all, others will not suffer from the refusal of ratification so that they cannot claim for damages.

Fourth, only the innocent parties are entitled to make the claim. Contrary to the German Civil Law, the subjective fault of the third party is not stipulated as the exemption. And it is pointed out by scholar that the parties mentioned here merely have ordinary negligence. In other words, those who aren't aware of the defect as a result of ordinary negligence should bear the corresponding liability. [4] For those who own gross negligence, they must be held completely accountable. After all, negligence is inevitable in a changing market especially when one is eager to conclude the transaction.

\subsection{The Content of Liability for Unauthorized Agency}

The liability provided by the third paragraph is a kind of no-fault liability. Whether the unauthorized agent realizes the lack of agency or not, they all bear the same legal responsibility. This provision actually combines the contents of the first and second paragraphs of Section 179 of the German Civil Law, creating controversy in the interpretation and application of law.

As a method of undertaking liability, proving the loss is unnecessary when the other party only 
claim for performance. It leads to a lighter burden of proof and reduces the adverse consequence arising from the inability to provide evidence. The other party can also claim for damages, but there are different views on whether the object is the performance interest or reliance interest due to the unified regulation in spite of the subjective state of the agent, unlike the German Civil Law. In terms of the literal expression, the last sentence which suggests the limitation of damages seems to be the description of restriction of the reliance interest. But it is juxtaposed with specific performance, another method of liability through which the third party's performance interest can be realized. This unbalanced legislation inevitably causes the consequence that the third party usually chooses the way that is more favorable to himself, and the compensation provided by the provision as a method of liability actually loses its meaning in practice. If we interpret it as the liability to pay compensation for the loss of performance interest in order to achieve consistency, it may be unable to match the rule of limitation. And whatever subjective states the agents are, they all bear the same liability. It is too harsh for those innocent agents who don't realize they are unauthorized throughout the whole legal activities.

As for the exemption of liability for unauthorized agency, no mention seems to be made. Neither the subjective fault of the other party nor the limited capacity for civil conduct of agent is stipulated by the law. For the former, it has been denied explicitly according to the fourth paragraph of article 171 by saying that the other party who is held to be at fault shall be liable, together with the agent. For the latter, the lawmakers choose to keep silence. The General Rules of the Civil Law of the PRC does start the new chapter of the system of agency in China, but more problems remain to be solved in the future.

\section{Conclusion}

When the juristic act is not valid for the principal, the other party in good faith is entitled to claim against the agent to protect his legitimate interest. The agent makes the claim that he is recognized and he will perform juristic act under the scope of authorization, he should guarantee the principal is responsible for his act. That is the point held by this essay: the liability occurs from the statutory guarantee. The subjective fault is not essential to the establishment of liability, but influences the method and extent. The reasonable difference provided by German Civil Law reflects the justice in civil law. We can absorb the quintessence and refine our legal provisions. Try to balance the interests of the actor and the third party on the basis of guaranteeing the transaction security, so that we can finally realize the original intention of the legislation of agency.

\section{References}

[1] Werner Flume. Das rechtsgeschaft [M]. Beijing: Law press, 2013. 956

[2] Ma Xinyan. The legislation of agency in the General Rules of the Civil Law of the PRC [J]. The Jurist. 201624 (5) 121-138

[3] Chi Ying. The System of Unauthorized Agency in the General Rules of the Civil Law of the PRC [J]. Tsinghua University Law Journal, 201711 (3) 126

[4] Xie Hongfei. The Basic Theory and the Important System of the Legislation of Agency [J]. ECUPL Journal. 201619 (5) 64-74 